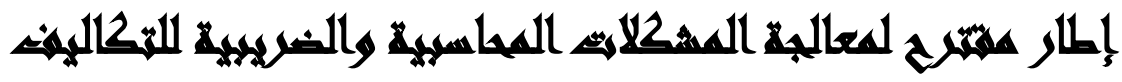

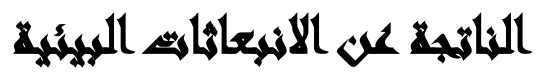

[11]

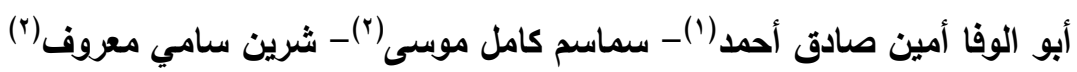

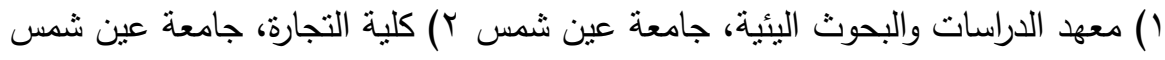
المستخلئ

استهدفت هذه الدراسة وضع إطار مقترح لمعالجة المشكلات المحاسبية والضربيية

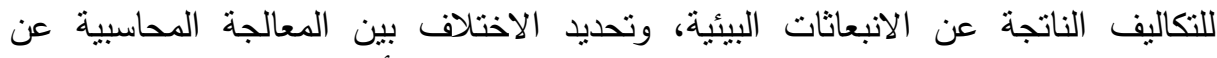

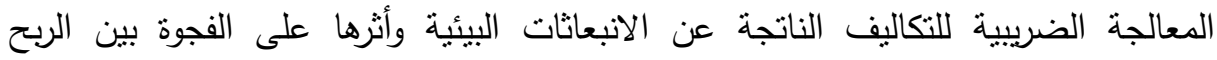
المحاسبي والربح الضريبي.

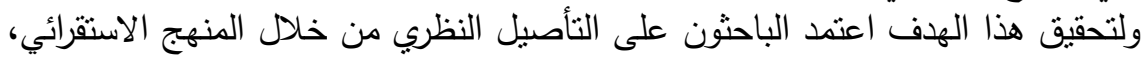

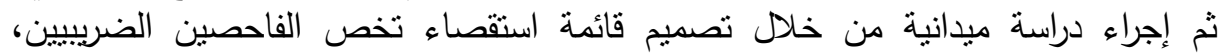

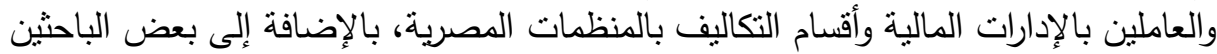

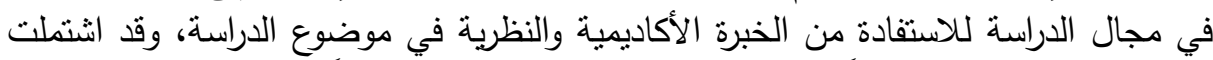

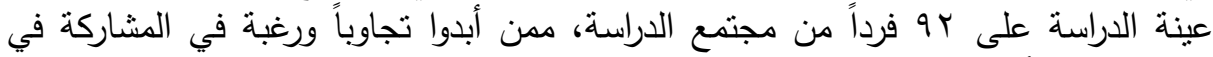

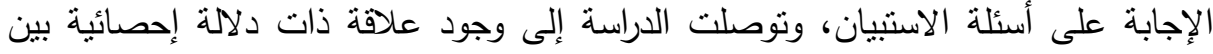

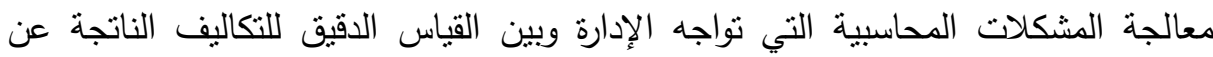

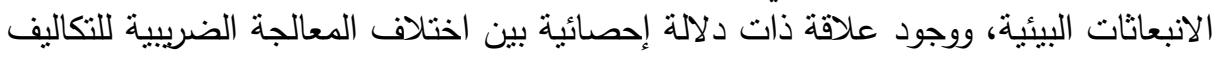

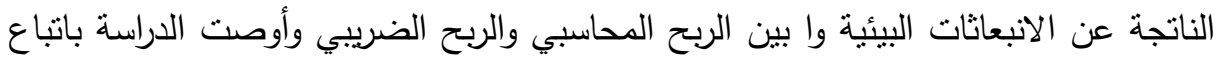

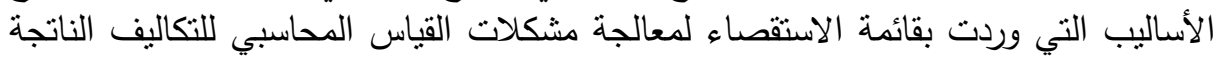

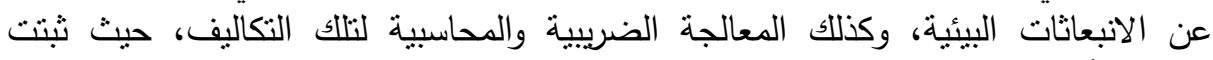
فعاليتها وأهميتها من وجهة نظر الثينة وكينة البحث.

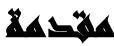

إن تحديد مفهوم دقيق للدحاسبة الضريبية على التلوث الناتج عن الانبعاثات البيئية يتطلب القيام بدراسة لكل من مفهوم المحاسبة، والضريبة، والتلوث الناتج عن الاتبعاثات البيئية على حدة لمحاولة ربط تلك المفاهيم معا ربطا سليما يعكس مدى تفاعل تلك المفاهيم كل مع

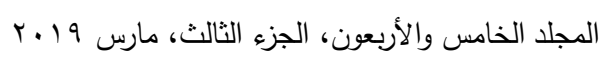


الآخر للوصول إلى صباغة تعبر عن مفهوم واضح للمحاسبة الضريبية على التلوث البيئي،

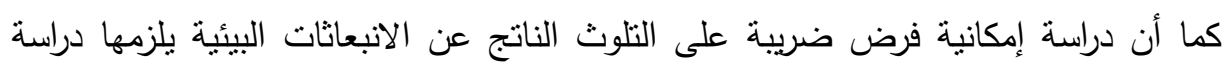

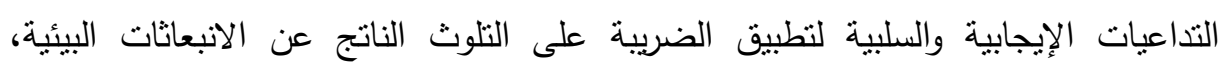
ودراسة تأثير فرض ضريبة على التلوث الناتج عن الانبعاثات البيئية على الحصيلة الإجمالية

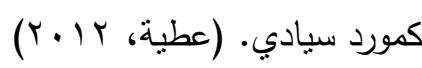

وسعياً لتحقيق التنمية الاقتصادية والاجتماعية في مصر قام المشرع المصري بإصدار

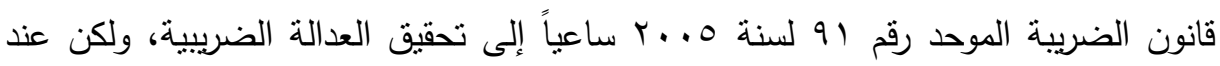

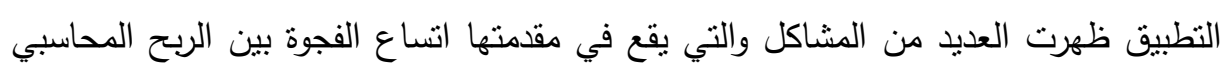

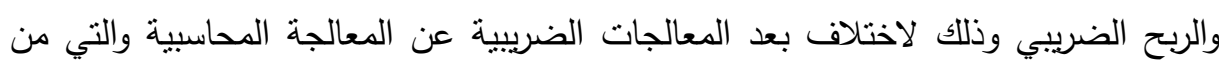
ضمنها اختلاف المعالجة الضريبية عن المعالجة المحاسبية للنكاليف الناتجة عن الانبعاثات

ويأتي اتساع الفجوة بين الربح المحاسبي والربح الضريبي نظراً لاختلاف المعالجات

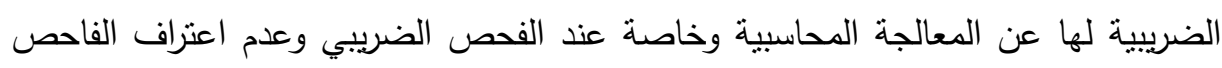

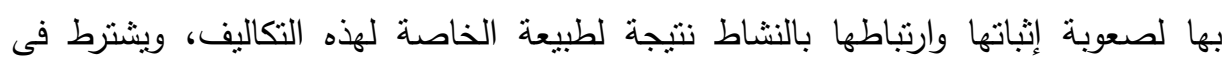
التكاليف والمصروفات واجبة الخصم ما يأني: أ-أن تكون مرتبطة بالنشاط التجاري أو الصناعي للمنشأة ولازمة لمزاولة هذا النشاط.

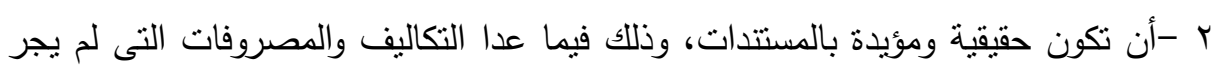
العرف على إثباتها بمستندات.

ومن هنا تأني أهمية البحث فى محاولة إظهار الفجوة بين الربح المحاسبي والربح

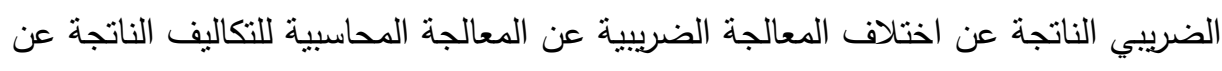

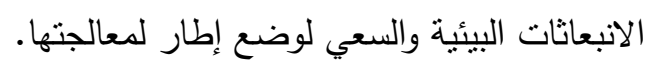

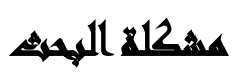

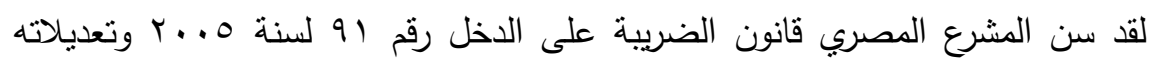
ساعياً إلى تحقيق المزيد من الاسنقرار الاقتصادي والضريبي ولكن مع بدء التطبيق العملي

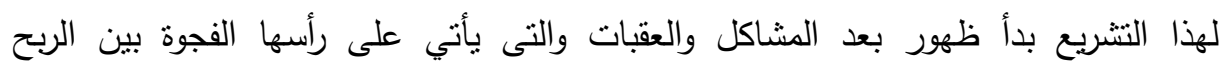
260

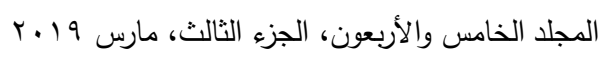


المحاسبي والربح الضريبي نتيجة لاختلاف بعض المعالجات الضريبية عن المعالجة

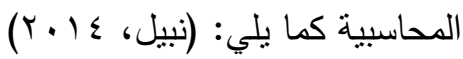

عدم وجود مفهوم محدد للتكاليف الناتجة عن الانبعاثات البيئية في الأدب المحاسبي أدى إلى ظهور عقبات في عملية قياسها وصعوبة الاتفاق على معالجة محاسبية لها. الطبيعة الخاصة للتكاليف الناتجة عن الانبعاثات البيئية من حيث صعاته صعوبة النية التأييد المستتدي لها وصعوبة إنبات العلاقة بينها وبين نشاط الوحدة، يمثلان عقبة أساسية للاعتراف الضريبي بها من ضمن التكاليف واجبة الخصم. يأتي الاختلاف بين المعالجة المحاسبية والمعالجة الضريبية للتكاليف الناتجة عن

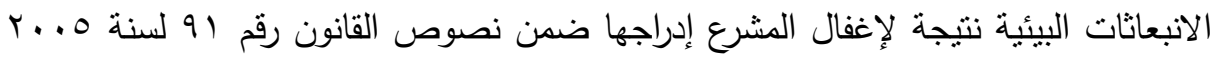

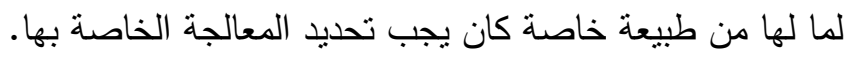
أغفلت السلطات التنفيذية (مصلحة الضرائب العامة) إدراج بند خاص للتكاليف الناتجة عن الانبعاثات البيئية في الإقرار الضريبي حتى يساعد على وضع أسس (أو توحيد) للمعالجة

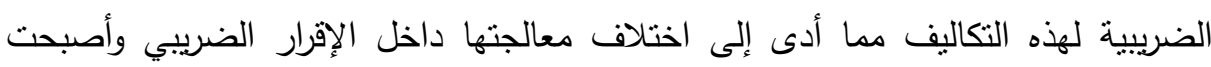
تتوقف على وجهة نظر معدي الإقرار، وفي مرحلة الفحص الضريبي ينوقف على رؤية الفاحص ومدي اقتتاعه بها. ومن هنا تكمن مشكلة البحث في الاختلاف بين المعالجة المحاسبية للتكاليف الناتجة عن الانبعاثات البيئية وبين المعالجة الضريبية لها، وفي ظل الافتقار لدراسات تتتاول ذللك فإنه يمكن صياغة مشكلة البحث من خلال التساؤل التالي: ما مدى الاختلاف في المعالجة الضريبية للتكاليف الناتجة عن الانبعانات البيئية عن

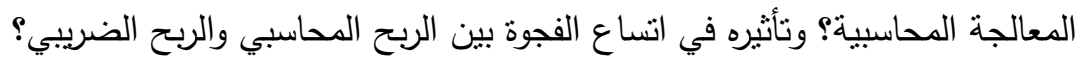

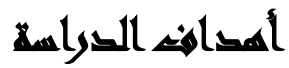

يتمنل الهدف الأساسي للبحث في "وضع إطار مقترح لمعالجة المشكلات المحاسبية والضريبية للتكاليف الناتجة عن الانبعاثات البيئية" ويتم تحقيق الهدف من خلال مجموعة من الهن

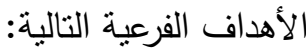


• توضيح مفهوم التكاليف الناتجة عن الانبعاثات البيئية وطبيعتها ومثاكل قياسها والمعالجة

المحاسبية لها.

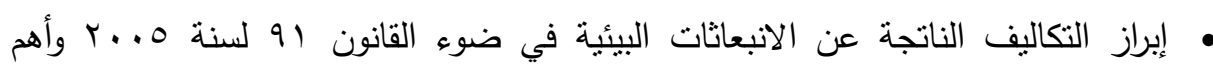
عقبات ومشاكل التطبيق. • التعرف على المشكلات المحاسبية لفرض ضريبة على التلوث الناتج عن الانبعاثات البيئية.

• تحديد الاختلاف بين المعالجة المحاسبية عن المعالجة الضريبية للتكاليف الناتجة عن الانبعاثات البيئية وأثزها على الفجوة بين الربح المحاسبي والربح الضريبي.

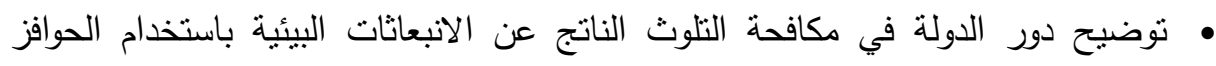
الاقتصادية الإيجابية والسلبية.

\section{هروز القواسمة}

الفرض الأول: لا توجد علاقة ذات دلالة إحصائية بين معالجة المشكلات المحاسبية التي هركي تواجه الإدارة وبين القياس الدقيق للتكاليف الناتجة عن الانبعاثات البيئية.

الفـرض الثـاني: لا توجد علاقـة ذات دلالـة إحصـائية بين اختلاف المعالجـة الضـريبية

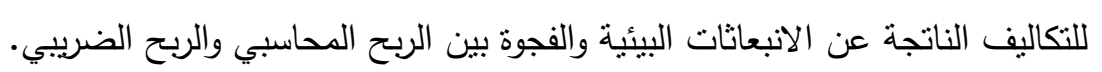

\section{مبورت التورامة}

• تقتصر الدراسة على الفترة الزمنية منذ تطبيق قانون الضريبة على الدخل رقم او لسنة

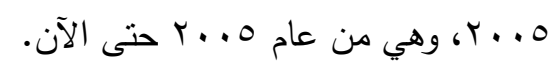

• تقتصر الدراسة على التكاليف الناتجة عن الانبعاثات البيئية في الصناعات الان الكيماوية والصناعات الدوائية وصناعة الإسمنت والصناعات البترولية. 


\section{منهجية القراسة}

في ضوء طبيعة المثكلة وهدف البحث اعتمد الباحثون على منهجين أساسيين في إعداد البحث هما:

(المنهج الاستقرائي: حيث قام الباحثون بالاطلاع واستقراء الدراسات العلمية التي تتاولت موضوع البحث من خلال إنباع أسلوب الدراسة المكتبية والاطلاع على الكتب

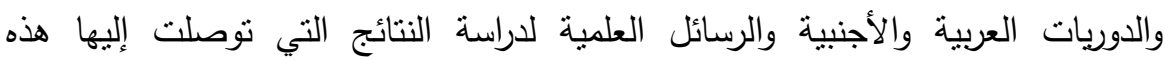
الدراسات والاستفادة منها في تحليل واختبار الفروض الأساسية التي يقوم عليها البحث والمتعلقة بمفهوم التكاليف الناتجة عن الانبعاثات البيئية وقياسها والمعالجة المحاسبية والضريبية لها ومدي علاقتها بالفجوة بين الربح المحاسبي والربح الضريبي. r) المنهج الاستنباطي: استخدم الباحثون هذا المنهج بهدف الكثف عن النتائج المنطقية المترتبة على اختبار الفروض الأساسية للبحث وذلك باختبار الإطار النظري والذي نم التوصل اليه من خلال المنهج الاستقرائي إحصائيا من خلال الدراسة الميدانية والتي لإسي الإسي

$$
\text { اعتمدت على الآتي: }
$$

- المقابلات مع الفاحصين الضريبين والعاملين بالإدارة المالية بالمنظمات محل الدراسة.

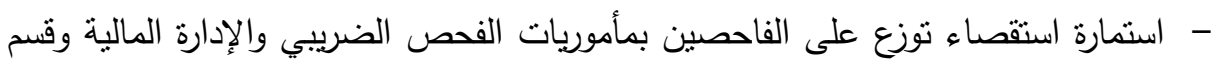
التكاليف في المنظمات والمنشأت محل الدراسة.

\section{أهمية القواسمة}

تتمنل أهية الدراسة في جانبين الجانب العلمي (الأكاديمي) والجانب العملي (التطبيقي). (الأهمية العلمية للبحث: 1-نتبع أهمية الدراسة من كونها توفر للمهتمين بالتكاليف الناتجة عن الانبعاثات البيئية الفهر

$$
\text { الكافي للمشكلات المحاسبية والضريبة المتعلقة بها. }
$$

r-ندرة الدراسات العربية، وقلة الدراسات الأجنبية التي تتتاول العلاقة بين الربح المحاسبي لهابي والربح الضريبي وأثر التكاليف الناتجة عن الانبعاثات البيئية على كل منهما. 
r-الاستفادة من البحث في تطوير الإطار الفكري في المعالجة المحاسبية والمعالجة الضريبية للتكاليف الناتجة عن الانبعاثات البيئية.

Y) الأهمية العملية للبحث: تعتمد أهمية البحث العملية في العمل على تقليل الفجوة بين الربح المحاسبي والربح الضريبي والمساعدة في وضع إطار مقترح لمعالجة المشكلات

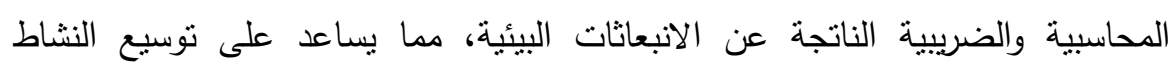

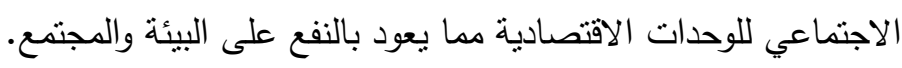

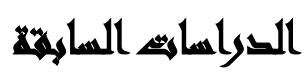

\section{( ) دراسات تتعلق بالفجوة بين الريح المحاسبي والريح الضريبي:}

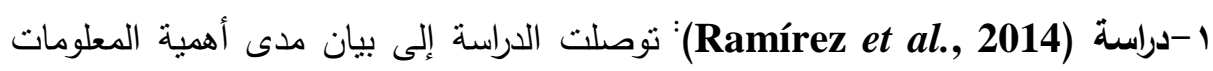

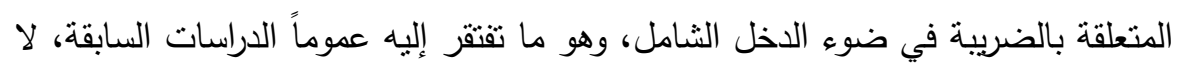

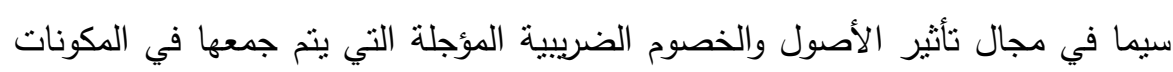

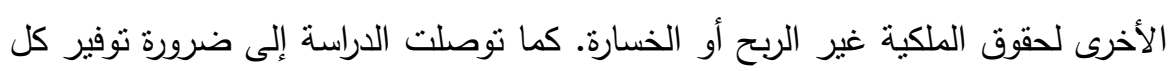
المعلومات التي تساعد المستثمرين على توقع التدفقات النقدية المستقبلية للثركة فيما يتعلق بالمزايا الضريبية. ووفقاً لذلك، يجب الإفصاح عن طبيعة وشروط الفروق المؤقتة

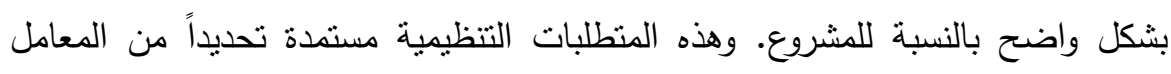
السلبي الذي لوحظ بالنسبة للأصول الضريبية، لأنه يؤدي إلى ضرورة أن تصبح مواقف لهن

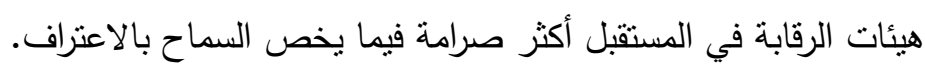

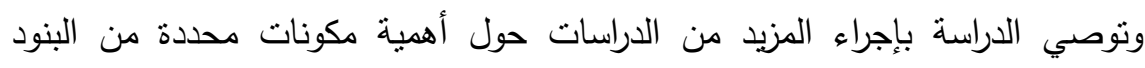

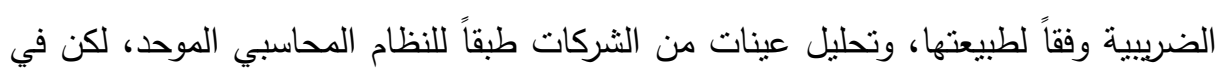
بيئات مالية مختلفة.

r براسة (Jiraskova \& Molin, 2015): توصلت الدراسة إلى وجود شركات تتشيكية

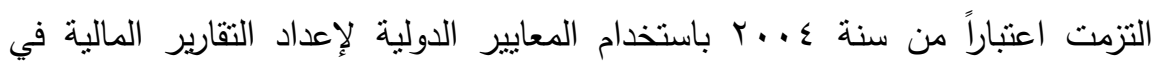
إمساك الدفاتر وإعداد الثقارير المالية رغم أن المعايير الدولية لإعداد النقارير المالية

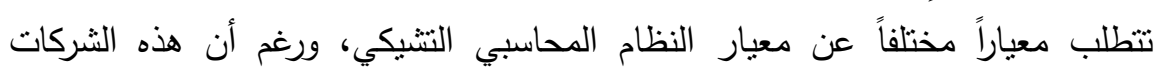

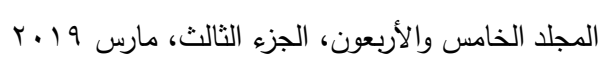


تستثمر الكثير من المال في تغيير برامج المحاسبة، وتدريب العاملين بالإدارة والمحاسبة، إلا أنه يجب أن تغير أسلوبها المحاسبي تغييراً كلياً. كما توصلت الدراسة إلى أنه حيث تقوم هيئة مستقلة بوضع المعايير الدولية لإعداد الدياد

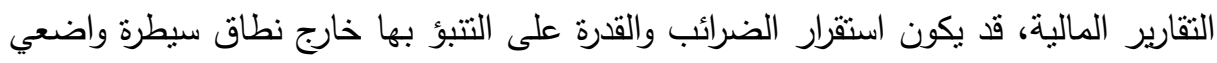

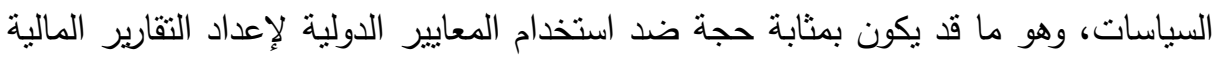
كنقطة انطلاق لفرض الضرائب. وتوصي الدراسة بضرورة حل مشكلة مصدري الأوراق المالية الناجمة عن الصيغة المخنلفة لقانون الضرائب والمحاسبة، وايجاد إمكانية لحل مشكلة ازدواج إعداد التقارير (للمحاسبة وللضرائب) - للسماح بفرض الضريبة على هذه الثركات بالنسبة للربح أو الخسارة

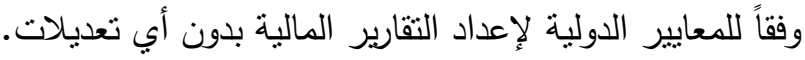

\section{r الدراسات السابقة المتعلقة بالتكاليف الناتجة عن الاتبعاثات البيئية}

1-دراسة (Sief, 2014): توصلت الدراسة إلى ضرورة إلزام المنشآت بالقياس المحاسبي

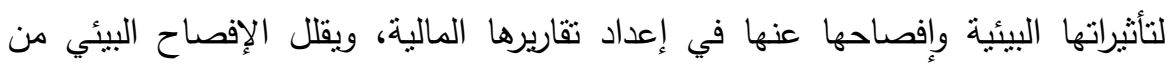

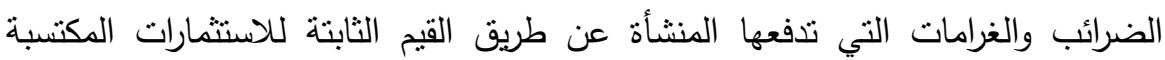
لحماية البيئة. لكن يوجد الكثير من المعوقات التي تقيد المنشأة في الإفصاح المحاسبي

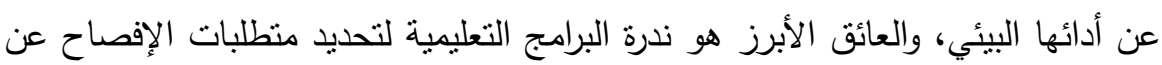

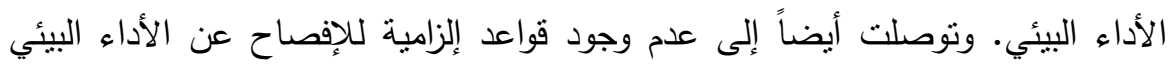
ووجود صعوبات في قياس التكلفة البيئية، وعدم الانسجام بين النظم المحاسبية التي تتبعها

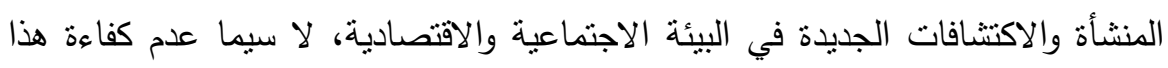

$$
\text { النظام في تحليل مكونات تكاليف الأداء البيئي. }
$$

وتوصي الدراسة بضرورة التكامل بين العوامل المنهجية والسياسات المحاسبية الملائمة في مجال تحليل عناصر تكاليف الأداء البيئي، وترابطها وعلاقتها بدورة نشاط المنشأة، ووجود بنك للمعلومات يساعد على إتاحة المعلومات لقياس مساوئ التلوث ومعالجتها، ونظام وسياسة ضريبية ملائمين للمحاسبة الاجتماعية والبيئية، وإنشاء نظام معلومات بيئية لتحسين إدارة

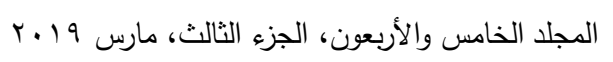


البيئة كثرط أساسي لامج الاعنبارات البيئية في الأنشطة المختلفة.

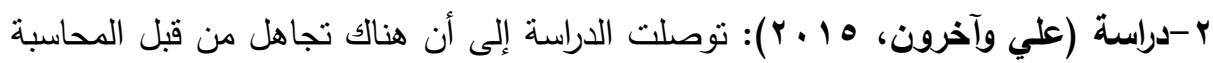

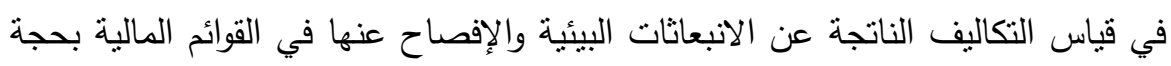

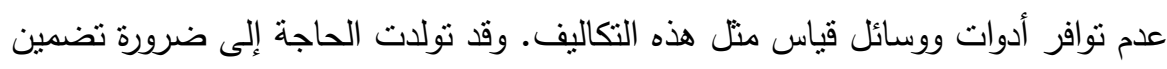
تلك القوائم البيانات الخاصة بتأثز أنشطة الوحدة الاقتصادية بالعاملين والمجتمع والبيئة

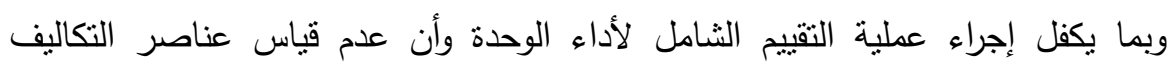

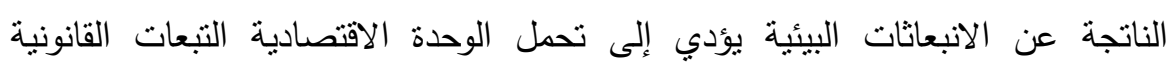
والاجتماعية والأخلاقية تجاه العاملين والبيئة والمجتمع.

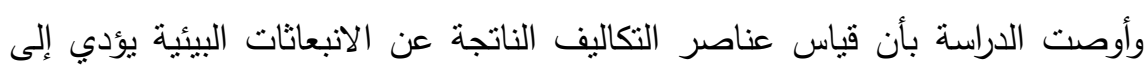

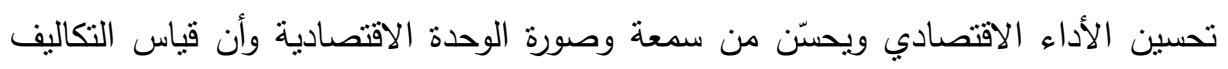

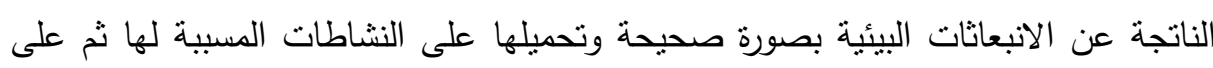
المنتجات يساهم في تحديد تكلفة المنتجات بشكل دقيق ومن ثم تحديد المقابلة السليمة بين إيراد المنتجات وتكاليفها. r) التعليق على الدراسات السابقة: يرى الباحثون في الجزء الأول من الدراسات السابقة، أن

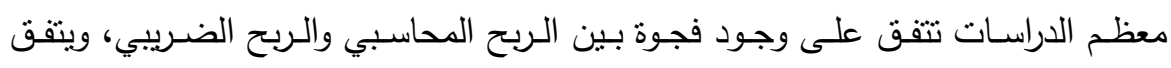

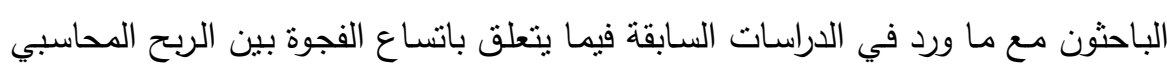

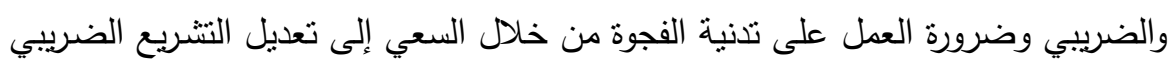
بما يتماشى مع معايير المحاسبة المصرية للقضاء على تللك الفجوة. كما أوضحت معظم الدراسات أن هناك تجاوز من قبل اللائحة التتفيذية لمواد القانون ومتمثلة في المادة • V وخروجها عن متطلبات القانون فيما يصل إلى عدم دستوريتها.

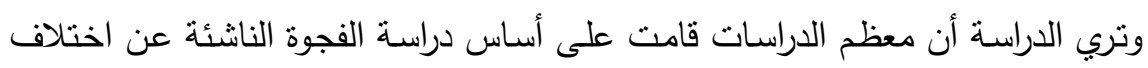

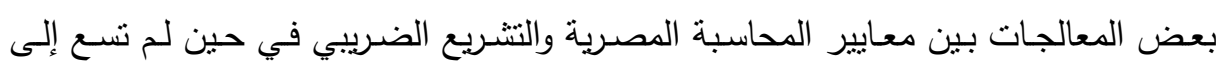

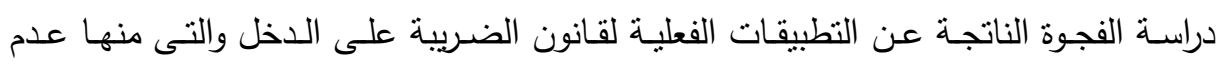

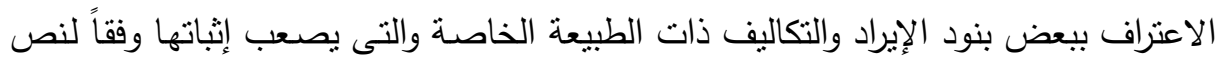

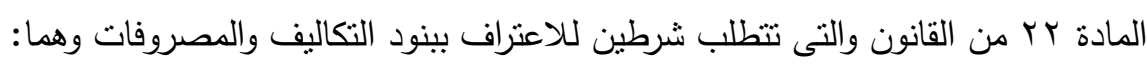


( ) أن تكون مرتبطة بالنشاط التجاري أو الصناعي للمنشأة ولازمة لمزاولة هذا النشاط.

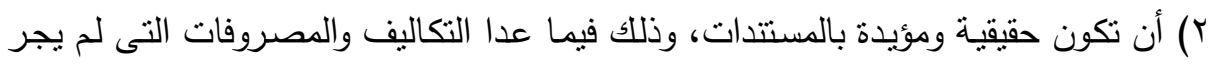
العرف على إنباتها بمستتدات.

كما يرى الباحثون أن أغلب الدراسات لم تأخذ في اعتبارها الأثار الناتجة عن التكاليف

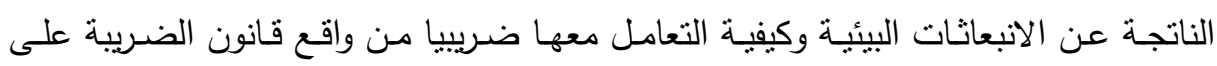
الدخل رقم او لسنة ه . . ب وركزت فقط على الفروق بين التعامل مـع بنود الهصروفات بوجها عام من وجهة النظر المحاسبية والمختلفة عنها من وجهة النظر الضريبية ومن هنا يسعى الباحثون من خلال تلاك الدراسة إلى إبراز هذا النوع من الفجوة بين النهر الربح

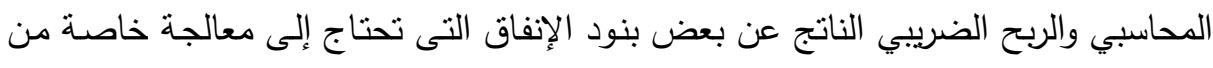

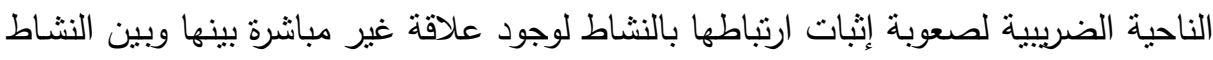
أو أن طبيعة هذه البنود تكون ذات تأييد مستندي ضعيف من وجهة النظر الضريبية.

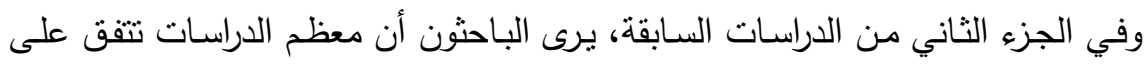

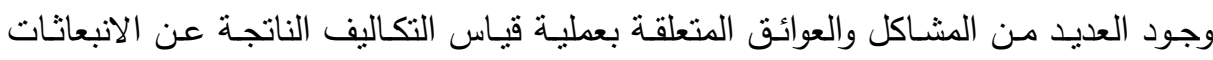
البيئية وأيضاً الإفصاح عن التكاليف الناتجة عن الانبعاثات البيئية وتحليل عناصر التكاليف لئه

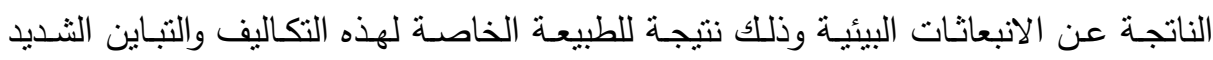

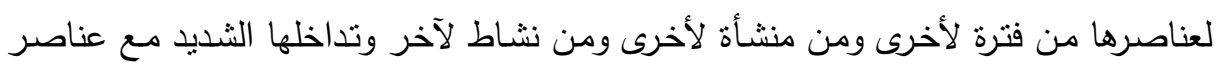

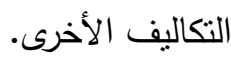
ويرى الباحثون أن صعوبة القياس والإفصاح عن التكاليف الناتجة عن الانبعاثات البيئية

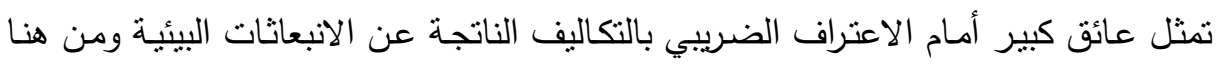

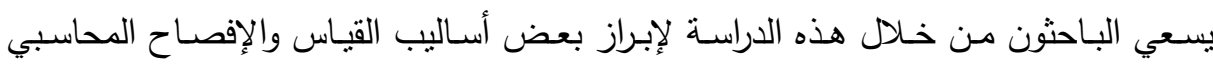

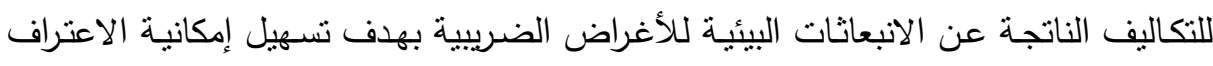
الضريبي بها لما له من أثر على حث المؤسسات على الإنفاق على الأنشطة البيئية. 


\section{الإسار النظليه للدواسما}

ولقد نتاول الباحثون في الدراسة بالتقصيل التكاليف الناتجة عن الانبعاثات البيئية في

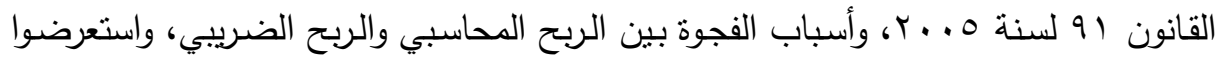

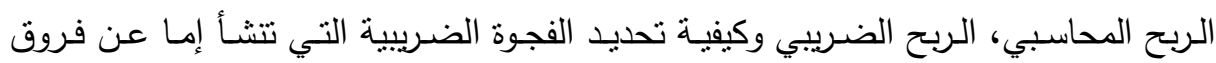
ضريبية دائمة أو فروق ضريبية مؤقتة، ثم نتاولوا أهم صور الاختلاف بين معايير المحاسبة

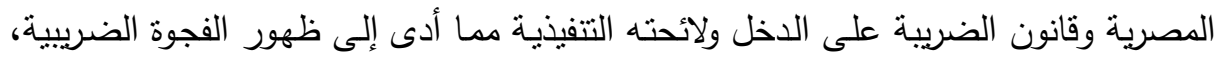

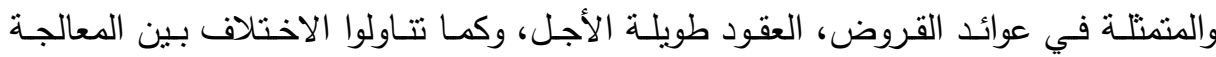

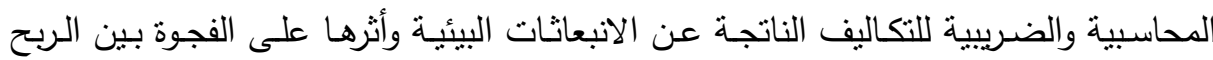
المحاسبي والربح الضريبي موضحين المشكلات المحاسبية لفرض ضريبة على التلوث الناتج

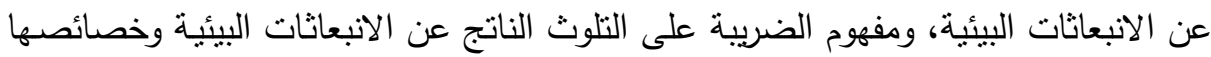

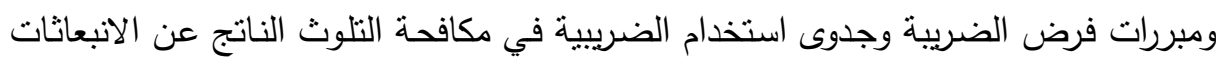

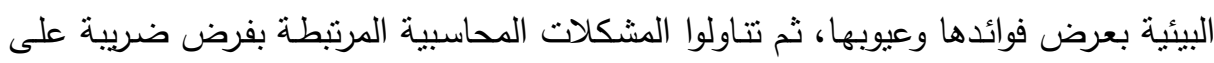
التلوث الناتج عن الانبعاثات البيئية في مصر المتمتلة في مشكلة القياس المحاسبي للوعاء

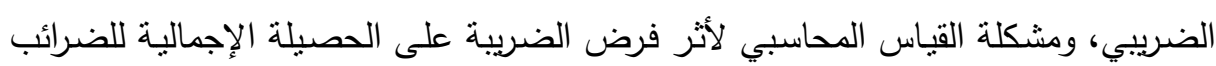
وعلى حماية البيئة وإزالة التلوث الناتج عن الانبعاثات البيئية وعلى الموقف التنافسي للمنشآت، لئل

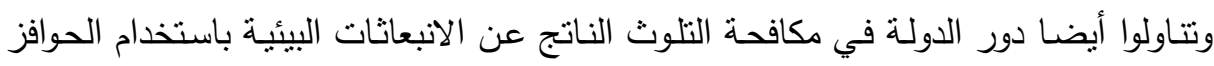
الاقتصادية الإيجابية والسلبية عن طريق فرض ضريبة على المنشآت والمصانع الملوثة للبيئة

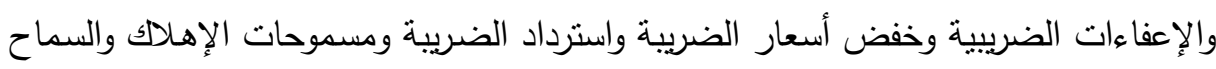
بخصم النفقات البيئية ضدن التكاليف واجبة الخصم.

\section{إجبراعايت ونمائيج الدواسمة}

الإجراءات المنهجية للاراسة: اعتمد الباحثون على المنهج الاستقرائي والاستتباطي بهدف الكثف عن النتائج المنطقية المنتبة على اختبار الفروض الأساسية للبحث وذللك

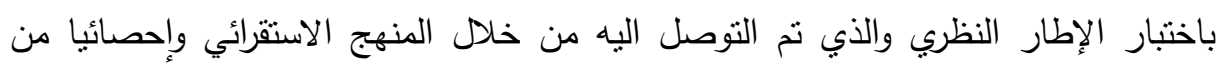
خلال الدراسة الميدانية والتي اعتمدت على الآتي: 
- - المقابلات مع الفاحصين الضريبين والعاملين بالإدارة المالية بالمنظمات محل الدراسة.

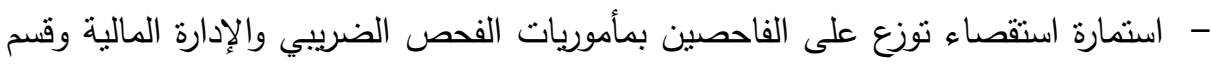
التكاليف في المنظمات والمنشأت محل الدراسة.

\section{متغيرات الاراسة ودرجة قياسها:}

المتغيرات المستقلة للفرض الأول: يتمنل في معالجة المشكلات المحاسبية التي تواجه الإدارة

والتي يمكن تقسيمها إلى المتغيرات الفرعية النالية:

1-مشكلات القياس المحاسبي للتكاليف الناتجة عن الانبعاثات البيئية

أ- مشكلة تحديد الأنشطة التي تقاس محاسبياً.

ب- مشكلة تحديد معايير القياس المحاسبي البيئي.

ج-مشكلة تحديد الإجراءات التي سنتبع في القياس المحاسبي البيئي.

د- صعوبات قياس التكاليف الناتجة عن الانبعاثات البيئية.

r-مشكلة قياس العوائد الناتجة عن الانبعاثات البيئية.

r-مشكلة الصعوبات التي نواجه المجتمع في القياس البيئي.

المتغير التابع للفرض الأول: دقة قياس التكاليف الناتجة عن الانبعاثات البيئية

المتغيرات المستقلة للفرض الثاني: اختلاف المعالجة الضربيية والمحاسبية للتكاليف الناتجة

عن الانبعاثات البيئية والتي يمكن تقسيمها إلى المتغيرات الفرعية التالية:

$$
\text { 1-مشكلة القياس المحاسبي للوعاء الضريبي. }
$$

ץ-مشكلة القياس المحاسبي لأثر فرض الضريبة على الحصيلة الإجمالية للضرائب كمورد

$$
\text { سيادي. }
$$

r-مشكلة القياس المحاسبي لأثز فرض الضريبة على حماية البيئة وإزالة التلوث الناتج عن

$$
\text { الانبعاثات البيئية. }
$$

ع-مشكلة القياس المحاسبي لأثر فرض الضريبة على الموقف التنافسي للمنشآت.

المتفير التابع للفرض الثاني: الفجوة بين الربح المحاسبي والربح الضريبي. 
مجتمع عينة الدراسة: بشمل مجتمع الدراسة الفاحصين الضرييين بمأموريات الفحص الضريبي، والعاملين بالإدارة المالية وقسم التكاليف بالمنظمات الدصرية، وكنلك البالكية الباحثين

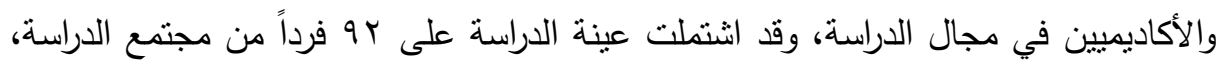
ممن شاركوا بالإجابة على أسئلة الاستنيان. مرحلة جميع اليبانات: لجمع بيانات الدراسة الميدانية قام الباحث بتصميم قائمة استقصاء تتفق الئق

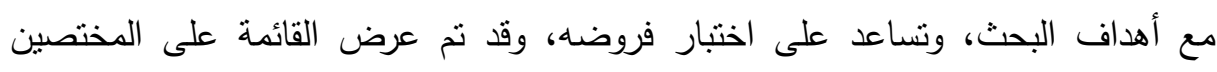
لتحكيمها، وقد اثنتلت على بيانات شخصية (المؤهل، الوظيفة، والخبرة) وثلاثة أسئلة بحثية:

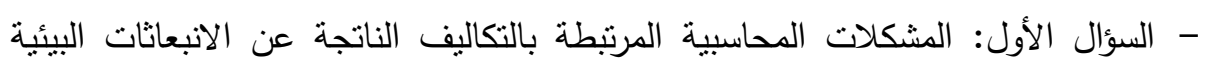
والعوائد وطرق معالجتها. - السؤال الثاني: المشكلات الضريبية المرتبطة بالنكاليف الناتجة عن الانبعاثات البيئية وطرق معالجنها. - السؤال الثالث: تأثير الاختلاف بين المشكلات المحاسبية المرتبطة بالتكاليف الناتجة عن

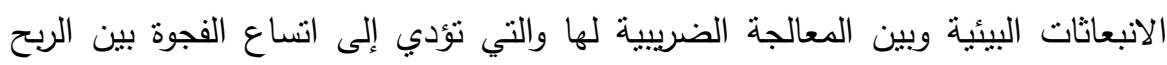

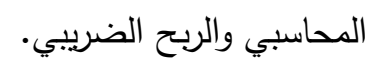
• قام الباحث بالاختبار القبلي Pre test لقائمة الاستيان، وذلك بتوزيعها على عينة

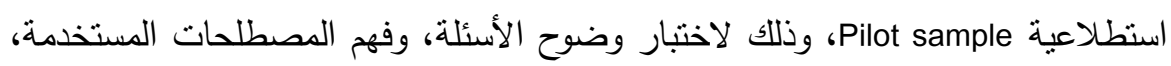

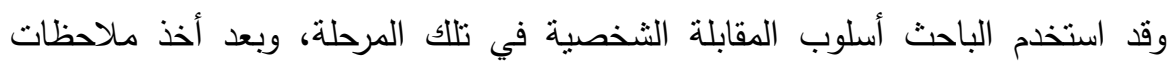

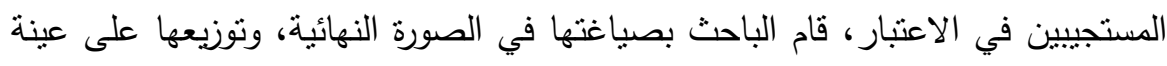
البحث، وبعد إعطائهم الوقت الكافي، قام بجمعها ومراجعتها واستبعاد غير الصالح منها. مرطلة ترميز البيانات - قام الباحثون بإعطاء رقم مسلسل لكل قائمة استقصاء ليسهل الرجوع إليها عند الحاجة،

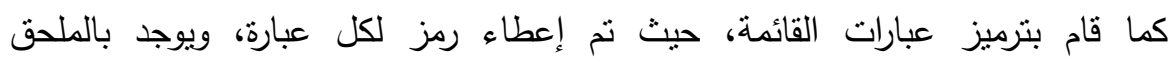
الإحصائي قائمة بالمتغيرات والرمز المستخدمة للرجوع إلئهة إليها عند الحاجة.

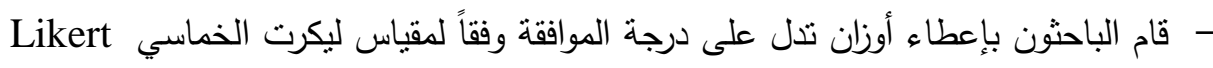

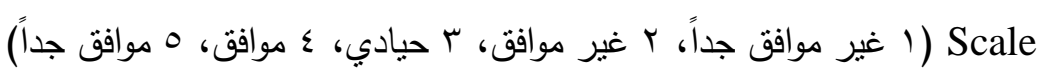

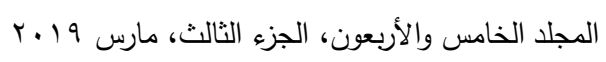


ولما كان مدى هذه الاستجابات (1-0=؛) يتوزع على 0 فئات، فيكون طول الفئة ^, •، لذا تتنير الدراسات إلى تقييم فئات المتوسط المرجح وفقاً لمعايير درجة الأهمية كما يلي:

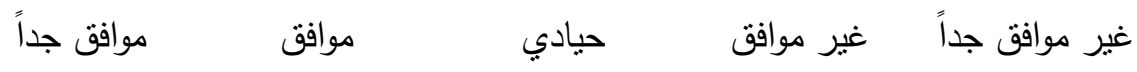
$0, \ldots-\varepsilon, r . \quad \varepsilon, 19-r, \varepsilon . \quad r, r q-r, r . \quad r, 09-1, \wedge . \quad 1, r q-1, \ldots$ ب- التحليل الإحصائي المستخدم: قام الباحثون بإدخال البيانات للحاسب الآلي، واستخدم

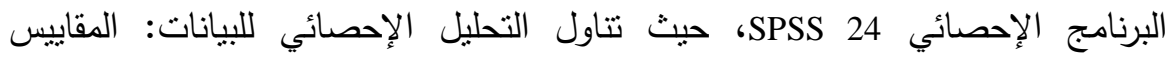

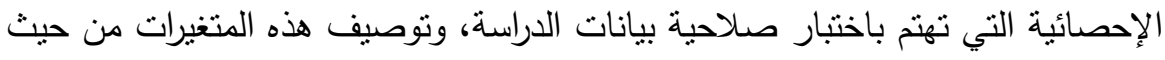

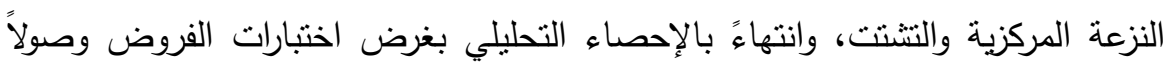
إلى نتائج البحث، وفيما يلي هذه المقاييس:

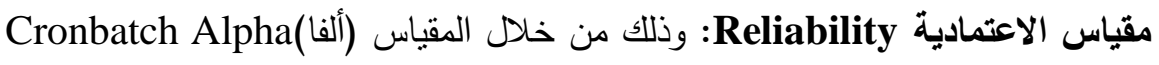

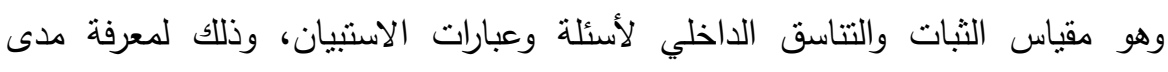
الموثوقية فى استجابات عينة البحث على أسئلة الاسنبيان، ومدى إمكانية تعميم نتائجها على مجتمع الدراسة. المتوسط المرجح Mean والانحراف المعياري Standard Deviation: لتوصيف متغيرات الدراسة من حيث النزعة المركزية والتتنت، مع الاستعانة بالجداول والرسوم البيانية التوضيحية. معامل ارتباط بيرسون: من خلال معامل ارتباط بيرسون يتم تحديد درجة واتجاه ودلالة

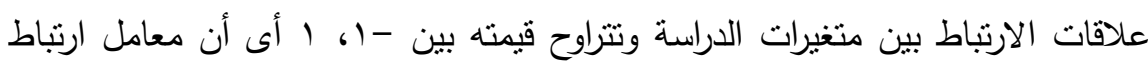

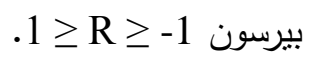
تحليل الانحدار المتدرج Stepwise Regression: تحليل الانحدار البسيط والمتعدد المتدرج Stepwise Multiple Regression Analysis لمعرفة آثز المتغيرات المستقلة على المتغير التابع وللتحقق من صحة فروض الدراسة. - معامل التحديد R: يبين دقة خط الانحدار في تقدير المتغير التابع باستخدام المتغير

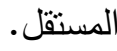


- اختبار (F test): يختبر معنوية نموذج الانحدار ككل، ونعتمد في الحكم على مستوى

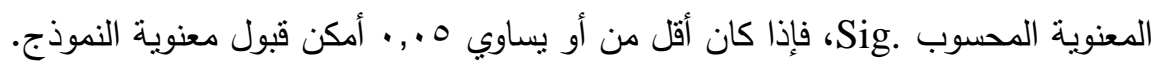

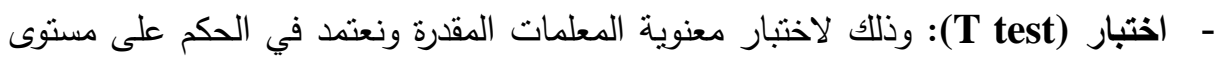

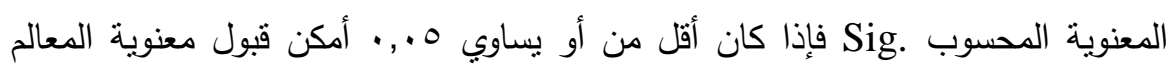
المقدرة.

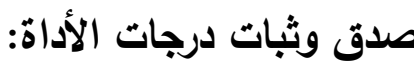

صدق الأداة: تعتبر الأداة صادقة إن كانت تقيس ما وضعت لقياسه، أو الصفة التي تهدف إلى قياسها. الثبات: معنى ثبات الاختبار أن يكون الاختبار مماثلاً لنفسه بمعنى أن يعطى نفس النتائج

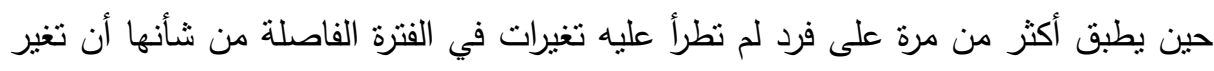
من الظاهرة التي يقيسها الاختبار . ويوضح ذلك مدئ مدى الإمكانية الاعتمادية على نتائج قائمة الإستنيان، ومدى إمكانية تعميم نتائجها على مجتمع الدراسة.

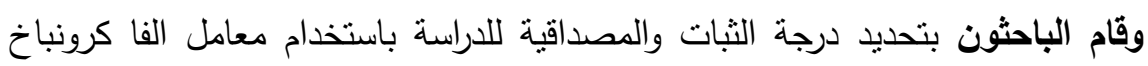
للتحقق من ثبات الأداة والاتساق الداخلي للتحقق من الصدق وبتضح ذلاده من التهات الجدول رقم

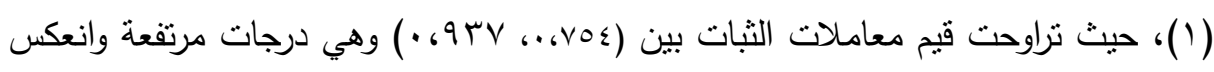

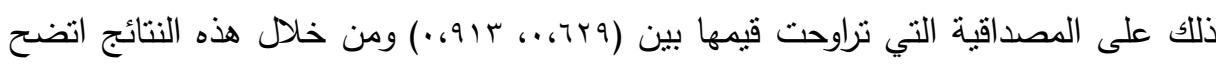
أن القائمة تتسم بالصدق والثبات، رقم (1) يوضح قيم معاملات الثبات والصدق لكل مجموعة 
جدول رقم (1) : يوضح معامل الثبات والصدق

\begin{tabular}{|c|c|c|c|}
\hline الصدق & $\begin{array}{l}\text { الثبات } \\
\text { Alfa } \\
\text { Alfa }\end{array}$ & العبارات & الأبعاد \\
\hline \multicolumn{4}{|c|}{ السؤال الأول: ا. مشكلات القياس الدحاسبى للتكاليف الناتجة عن الانبعاثات البيئية وطرق معالجتها: } \\
\hline$\cdot, 9 \cdot r$ & $\cdot, \Lambda) \leqslant$ & $\varepsilon$ & أ. مشكلة تحديد الأنشطة التى تقاس محاسبياً وطرق معالجتها \\
\hline$\cdot, 9 \leq 4$ & $\cdot, \wedge \wedge \wedge$ & $\varepsilon$ & ب. معالجتهلة تحديد معايير القياس المحاسبي البيئي وطرق \\
\hline$\cdot, \wedge \wedge \vee$ & $\cdot, \mathrm{VA} \vee$ & r & ج. البيئي وطكلة تحديد الإجراءات التي ستتبع في القياس المحاسبي \\
\hline$\cdot, \wedge \leq 7$ & $\cdot, \times 17$ & r & د. مشالجتلة قياس التكاليف الناتجة عن الانبعاثات البيئية وطرق \\
\hline$\cdot, 91 \mathrm{~V}$ & $\cdot, \wedge \varepsilon \cdot$ & r & r. كشكلة قياس العوائد الناتجة عن الانبعاثات البيئية \\
\hline., $9 \mu \mathrm{rr}$ & $\cdot, \wedge \vee 1$ & r & r. معالجة المشكلات التى تواجه المجتمع فى القياس الييئي \\
\hline \multicolumn{4}{|c|}{ السؤال الثانى: المشكلات الضريبية المرتبطة بالتكاليف الناتجة عن الانبعاثات البيئية وطرق معالجتها } \\
\hline$\cdot, \wedge 91$ & $\cdot, \mathrm{V} 9 \mathrm{~T}$ & $\varepsilon$ & 1. معالجة مشكلة القياس المحاسبى للوعاء الضريبي \\
\hline •, Var & • & r & 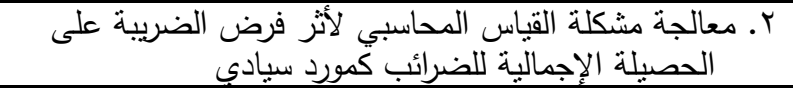 \\
\hline$\cdot, 90 \leqslant$ & $\cdot, 911$ & 1 & 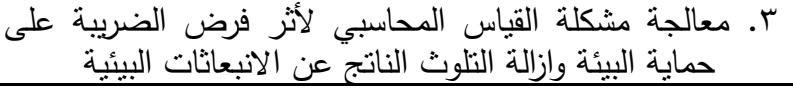 \\
\hline., 914 & 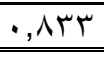 & $\underline{\varepsilon}$ & السؤال الثالث: الفجوة بين الربح المحاسبى والربح الضريبي \\
\hline
\end{tabular}

Spss المصدر: من مخرجات برنامج المبنج

\section{الإحصاء الوصفي لمتغيرات الاراسة:}

أولا: نتائج تحليل فقرات الدراسة لمعرفة آراء عينة الدراسة حول بعض المشكلات المحاسبية المرتبطة بالتكاليف الناتجة عن الانبعاثات البيئية والعوائد وطرق معالجتها كما يلي: يهدف الإحصاء الوصفي لمتغيرات الدراسة توصيف تلك المتغيرات من حيث النزعة المركزية (الوسط الحسابي، والوسط الحسابي النسبي)، والتشتت (الاتحراف المعياري، ومعامل الاختلاف) بهدف تحديد الأهمية النسبية لتالك المتغيرات وترتيبها حسب نلاك الأهمية من وجهة نظر عينة البحث، وفيما يلي نتائج توصيف المتغيرات كما يلي: 
أبو الوفا أمين صادق أحمد وآخرون

جدول رقم (ץ): مشكلات القياس المحاسبي للتكاليف الناتجة عن الانبعاثات البيئية وطرق معالجنها

\begin{tabular}{|c|c|c|c|c|c|c|}
\hline الموافقة & | الاتفاقة & $\begin{array}{c}\text { الاختلاف } \\
\text { \% } \\
\end{array}$ & | معياري & سبط & حسابي & المتغيرات \\
\hline موافق جداً & 10,0 & $1 \leqslant, 0$ & $\cdot, 74$ & $91, r$ & $\{, 07$ & 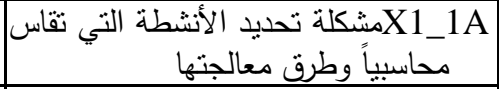 \\
\hline موائ3 & $\Lambda \varepsilon, \cdot$ & $17,$. & $\cdot, V T$ & $91, r$ & $\{, 07$ & 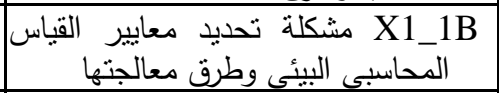 \\
\hline موافق جدا] & $\wedge \varepsilon, \wedge$ & $10, r$ & • & $9 \cdot, 1$ & $\varepsilon, 0$. & 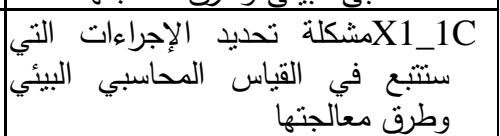 \\
\hline |موا & $\Lambda r, \varepsilon$ & $1 V, T$ & $\cdot, V\urcorner$ & ᄉ૭, £ & $\varepsilon, \pi r$ & 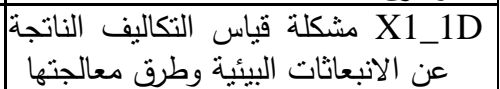 \\
\hline مو & $\Lambda r, r$ & $1 V, \varepsilon$ & $\cdot, \sqrt{ } \times$ & $\lambda \vee, r$ & \&, & 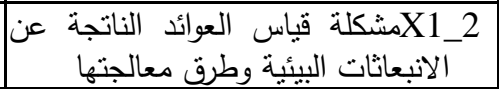 \\
\hline |موا & $\wedge r, 1$ & 17,9 & $\cdot, \mathrm{VV}$ & $9 \cdot, \wedge$ & $\{, 0 \leqslant$ & 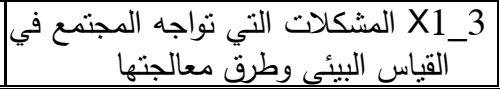 \\
\hline
\end{tabular}

ثانياً: نتائج تحليل فقرات الدراسة لمعرفة آراء عينة الدراسة حول بعض المشكلات الضريبية المرتبطة بالتكاليف الناتجة عن الانبعاثات البيئية وطرق معالجتهاتها كما يلي:

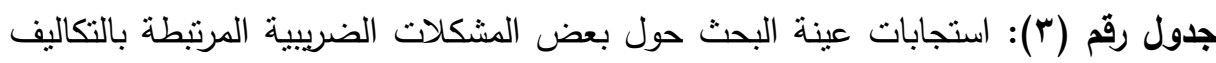
الناتجة عن الانبعاثات البيئية وطرق معالجتها

\begin{tabular}{|c|c|c|c|c|c|c|}
\hline لدوافقة & 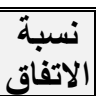 & الاختلافل & | معياري & نسبي حسبي & | حسابط & المتغيرات \\
\hline موافق | & $v 0,7$ & $r \leq, \varepsilon$ & $\cdot, 91$ & $\Lambda \cdot, r$ & $\varepsilon, \cdot Y$ & 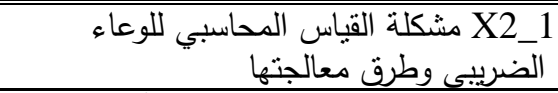 \\
\hline موافق & $V r, \Lambda$ & $r \uparrow, r$ & $1, \cdot 1$ & $V V, r$ & T, & 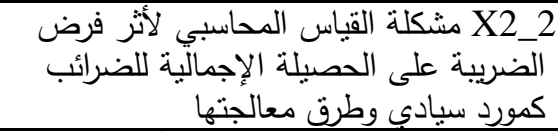 \\
\hline موافقِ & $\wedge, v$ & $1 \Lambda, r$ & $\cdot, \wedge$. & 17,9 & $\varepsilon, \Gamma \varepsilon$ & 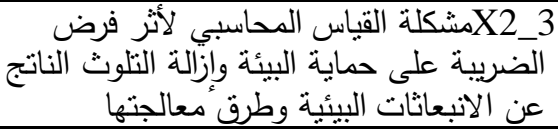 \\
\hline موافقٍ & $\wedge \cdot, \wedge$ & $19, Y$ & $\cdot, \wedge \vee$ & $q \cdot, v$ & $\varepsilon, 0 T$ & توافرت اعتبرت المنشأة صديقة للبيئة التئة التي إذا \\
\hline
\end{tabular}


ثالثاً: نتائج تحليل فقرات الدراسة لمعرفة آراء عينة الدراسة حول الفجوة بين الريح

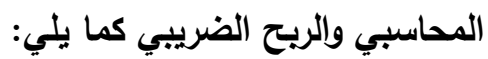
جدول رقم (ء): استجابات حول الفجوة بين الربح المحاسبي والربح الضريبي وطرق معالجتها

\begin{tabular}{|c|c|c|c|c|c|c|}
\hline | لمورة |لمقة & ناتفبة & $\begin{array}{c}\text { معامل الاختلف } \\
\%\end{array}$ & | معياري & | وسبط & وسط - وسطي & \\
\hline موافِّ & 11,7 & $1 \wedge, \varepsilon$ & $\cdot, \lambda 1$ & $\wedge \wedge, \cdot$ & $\varepsilon, \varepsilon$. & معالجنها بين الربح المحاسبي والربح الضريبي وطرق \\
\hline جدافٍ & $\vee \vee, \vee$ & $r \cdot, r$ & $\cdot, \wedge 9$ & $\wedge \vee, \imath$ & $\varepsilon, \Gamma \wedge$ & 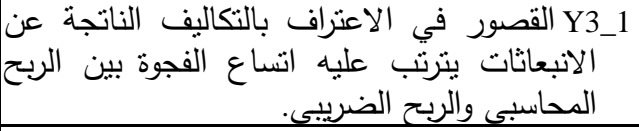 \\
\hline موافقٍ & $\Lambda \cdot, r$ & 19,1 & $\cdot, \wedge \wedge$ & $\wedge q, r$ & $\varepsilon, \varepsilon V$ & 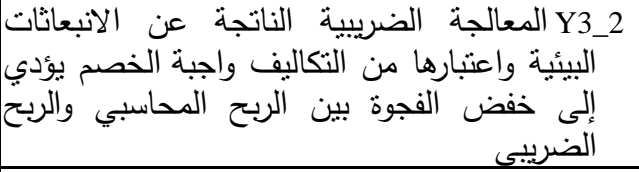 \\
\hline موافِ & $\vee \vee, Y$ & $r M, \Lambda$ & $1, \cdot r$ & $\wedge\urcorner, \vee$ & $\varepsilon, \Gamma \varepsilon$ & 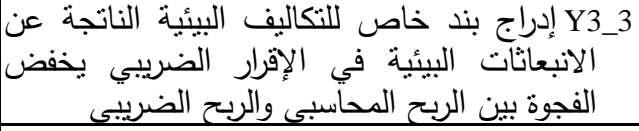 \\
\hline موافٍِ & $\vee \wedge, Y$ & YI,A & $\cdot, 97$ & $\wedge \wedge, 0$ & $\varepsilon, \varepsilon Y$ & 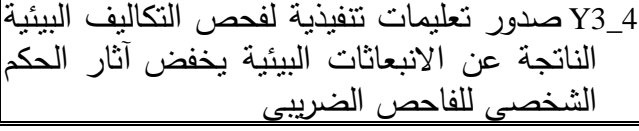 \\
\hline
\end{tabular}

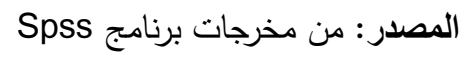

الختبار صحة فروض الدراسة:

الفرض الأول: لا توجد علاقة ذات دلالة إحصائية بين معالجة الششكلات المحاسبية الني تواجه الإدارة وبين القياس الدقيق للتكاليف النانجة عن الانبعاثات البيئية.

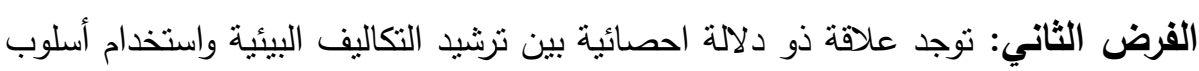

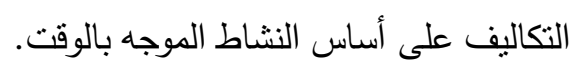
اختبار صحة فرض الدراسة الأول: لاختبار هذا الفرض نم إجراء تحليل الارتباط الخطي Correlation 
جدول رقم (•): نتائج الانحدار المتدرج بين القياس الدقيق للتكاليف الناتجة عن الانبعاثات البيئية كمتغير تابع، وبين معالجة المشكلات المحاسبية التي تواجه الإدارة

كمتغيرات مستقلة

\begin{tabular}{|c|c|c|c|}
\hline \multicolumn{4}{|c|}{ المتغير التابع Y1 "القياس الدقيق للتكاليف الناتجة عن الاتبعاثات البيئية" } \\
\hline المعنوية & اختبار & معاملات & المتغيرات المستقلة \\
\hline$\cdot, \cdot, \cdot$ & r, rVo & $\cdot, \Gamma \wedge \uparrow$ & ثابت الانحدار (Constant) \\
\hline$\cdot, \cdot \leq \cdot$ & Y,TVO & $\cdot, 1 \cdot V$ & X1_1B علاج مشكلة تحديد معايير القياس المحاسبي البيئي \\
\hline$\cdot, \cdots$ & $7, \cdot M$ & $\cdot$, YYO & علاج صعوبات التكاليف الناتجة عن الانبعاثات البيئية X1_1D \\
\hline$\cdot, \cdots$ & $\varepsilon, \vee T \varepsilon$ & $\cdot, Y_{1}$ & عاج المشكلات التى تواجه المجتمع في القياس البيئي X1_3 \\
\hline$\cdot, \cdot$ & $r, 0, \varepsilon$ & $\cdot, 191$ & الاج مشاسبلة البيئيد الإجراءات التي ستتبع في القياس \\
\hline$\cdot, \cdots 1$ & r,rAr & $\cdot, 1 \vee 0$ & علاج مشكلة تحديد الأنشطة التي تقاس محاسبياً X1_1A \\
\hline
\end{tabular}

دخلت المتغيرات في نموذج الانحدار وفقاً لقوة علاقتها بالمتغير التابع كما يلي:

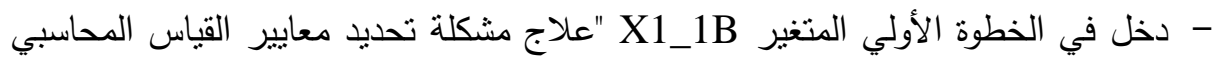
البيئي"، يلي ذلك المتغير X1_1D "علاج صعوبات التكاليف الناتجة عن الانبعاثات البيئية"، ثم المتغير X1_3 "علاج المشكلات التي نواجه المجتمع في القياس البيئي"، وفي الخطوة الرابعة المتغير X1_1C "علاج مشكلة تحديد الإجراءات التي ستتبع في القياس المحاسبي البيئي"، وفي الخطوة الأخيرة المتغير X1_1A "علاج مشكلة تحديد الأنشطة التي تقاس محاسبياًا. - استبعد النموذج X1_2 "علاج مشكلة قياس العوائد الناتجة عن الانبعاثات البيئية"، لقوة ارتباطه بالمتغيرات المستقلة السابق دخولها في معادلة الانحدار . بعد ثقدير معاملات الانحدار أخذ نموذج الاتحدار الصيغة التالية

\section{$Y 1=0.386+0.107 * X 1 \_1 B+0.225 * X 1 \_1 D+0.21 * X 1 \_3+0.191 * X 1 \_1 C$}

$+175 * X 1 \_1 A+\varepsilon$

القرار رفض فرض الدراسة: لا توجد علاقة ذات دلالة إحصائية بين معالجة المشكلات المحاسبية التي تواجه الإدارة وبين القياس الدقيق للتكاليف الناتجة عن الانبعاثات البيئية. 
اختبار صحة فرض الدراسة الثاني: لا نوجد علاقة ذات دلالة إحصائية بين اختلاف المعالجة الضريبية للتكاليف الناتجة عن الانبعاثات البيئية والفجوة بين الربح المحاسبي والربح

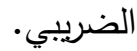
ولاختبار هذا الفرض تم إجراء تحليل الارتباط الخطي Correlation، وتحليل الانحدار المتدرج Stepwise Regression، وجاءت النتائج كما يلي: جدول رقم (؟): نتائج الانحدار المتدرج بين بين الفجوة بين الربح المحاسبي والربح الضريبي كمتغير تابع، وبين معالجة اختلاف المعالجة الضريبية للتكاليف الناتجة عن

الانبعاثات البيئية كمتغيرات مستقلة

\begin{tabular}{|c|c|c|c|}
\hline \multicolumn{4}{|c|}{ المتغير التابع Y3 "الفجوة بين الربح المحاسبي والريح الضريبي" } \\
\hline $\begin{array}{l}\text { المعنوية } \\
\text { Sig. } \\
\end{array}$ & $\begin{array}{c}\text { (ختبار } \\
\\
\end{array}$ & معاملات & المتغيرات المستقلة \\
\hline$\cdot, \cdot r$ & $r, Y \cdot V$ & $1, r 9 \leq$ & ثابت الانحدار (Constant) \\
\hline$\cdot, \cdot 1 \cdot$ & 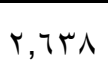 & $\cdot$, & 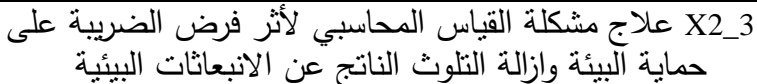 \\
\hline 10 & r, $₹ 9$. & $\cdot, r \cdot$ & 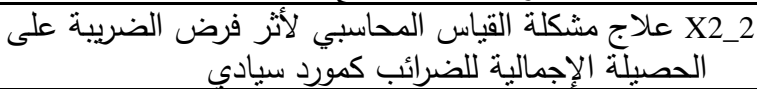 \\
\hline$\cdot, \cdot T V$ & r, ror & $\cdot$, YO. & الموقف التتافسي للمنشآت القياس المحاسبي لأُّر فرض الضريبة على \\
\hline
\end{tabular}

R square $=0.37 \quad$ F $=17.25 \quad$ Sig. $=0.000$

$$
\text { من الجدول يتضح ما يلي: }
$$

دخلت المتغيرات في نموذج الانحدار وفقاً لقوة علاقتها بالمتغير التابع كما يلي:

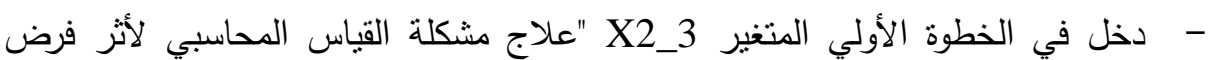

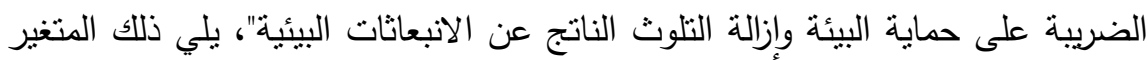
X2_2

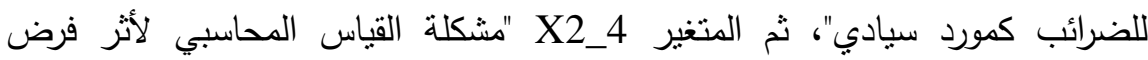

$$
\text { الضريبة على الموقف التتافسي للمنشآت". }
$$

- استبعد النموذج X2_1 "علاج مشكلة القياس المحاسبي للوعاء الضريبي"، لقوة ارتباطه بالمتغيرات المستقلة السابق دخولها في معادلة الانحدار . 
بعد تقدير معاملات الانحدار أخذ نموذج الانحدار الصيغة التالية

\section{$Y 3=1.394+0.3 * X 2 \_3+0.2 * X 2 \_2+0.25 * X 2 \_4+\varepsilon$}

القـرار رفض فرض الدراسة: لا نوجد علاقة ذات دلالة إحصائية بين اختلاف المعالجة

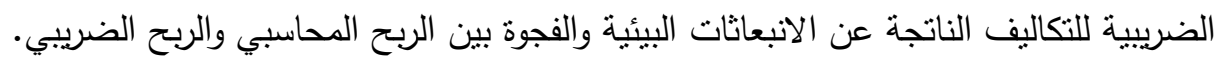

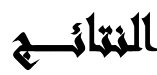

\section{أولاً: نتائج خاصة باختبار صلاحية البيانات:}

•أنتتت معاملات الارتباط بين العبارات والأبعاد التي تتنمي إليها أنها ذات دلالة معنوية عند مستوى معنوية ا. ,. • مما يدل على التتاسق الداخلي Internal Consistency لعبارات

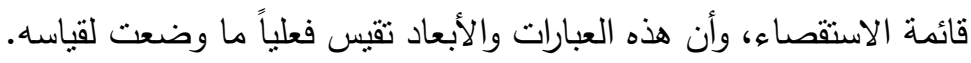

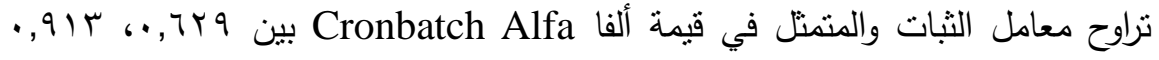

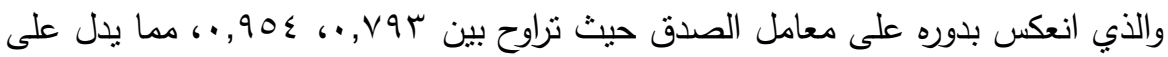
ثبات استجابات عينة البحث، وإمكانية تعميم نتائج الدراسة على مجتمع الدراسة.

\section{ثانياً: نتائج خاصة بتوصيف المتغيرات:} • جاء مستوى الموافقة "موافق جداً" على مشكلة تحديد الأنشطة التي تقاس محاسبيا، وقد

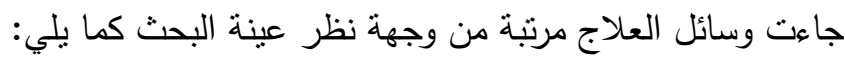
- ت تحديد الأهداف البيئية. - فهم طبيعة ومدى ملاعمة أساليب المحاسبة البيئية باختلاف أساليب وممارسات المؤسسات

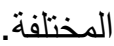

$$
\text { - تحديد الأنثطة البيئية الواجب التعامل معها. }
$$

جاء مستوى الموافقة "موافق جدا" على مشكلة تحديد معايير القياس المحاسبي البيئي، وقد جاءت وسائل العلاج مرنبة من وجهة نظر عينة البحث كما يلي:

$$
\text { - }
$$

- الاتفاق على معايير للقياس المحاسبي للأنشطة البيئية متفق عليها وأن تلقى قبول عام لدى بلى 
- أن تستجيب المعايير للتغييرات البيئية التي تحدث في المستقبل. - أن تسهل المعايير إمكانية إجراء عملية القياس في حدود التكلفة العادية وفي ظل القيود المفروضة في نظام المعلومات.

جاء مسنوى الموافقة "موافق جداً" على مشكلة تحديد الإجراءات التي سنتبع في القياس

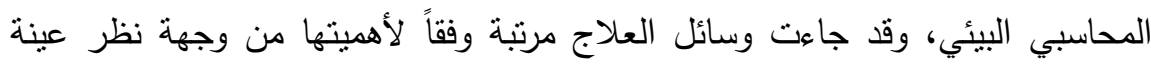
البحث كما يلي: - التعرف على الأنشطة البيئية التي تمارسها المؤسسة في البيئة.

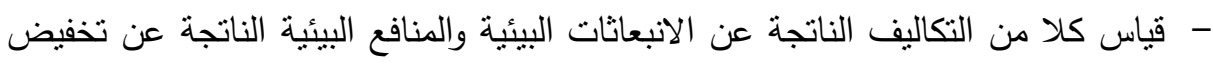
تكاليف برامج الرقابة على عناصر تلوث البيئة. - - دراسة السياسات البيئية التي تتفذها المؤسسة وذلك حتى ينت توضيح نسب التلوث المسموح بها والتأثير البيئي. جاء مستوى الموافقة "موافق جداً" على مشكلة قياس التكاليف الناتجة عن الانبعاثات

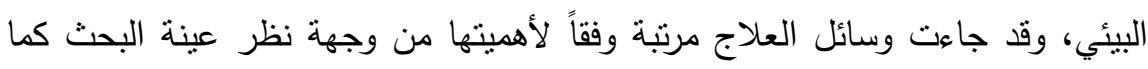
- حصر عناصر التكاليف الناتجة عن الانبعاثات البيئية - - ربط التكاليف بالعوائد الناتجة عن الانبعاثات البيئية المتولدة عن الأداء خلال نفس الفترة. - فصل التكاليف الناتجة عن الانبعاثات البيئية عن التكاليف الاقتصادية والاجتماعية. • جاء مسنوى الموافقة "موافق جداً" على مشكلة قياس العوائد الناتجة عن الانبعاثات البيئي، وقد جاءت وسائل العلاج مرتبة وفقاً لأهميتها من وجهة نظر عينة البحث كما يلي: - التحديد الدقيق للإيرادات الناتجة عن إعادة تتغيل بعض عناصر التلوث البهات البيئي. - التحديد الدقيق لبعض أنواع العوائد المباشرة للأنشطة البيئية. - توفير البرامج والأنشطة البيئية المتعددة الأهداف التي يمكن قياسها كمياً في كثنر من لنئن الأحيان. 
جاء مستوى الموافقة "موافق جداً" على المشكلات التي تواجه المجتمع في القياس البيئي،

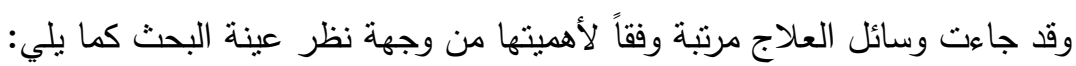

- توفير كوادر فنية مؤهلة للعمل في مجال حماية البيئة.

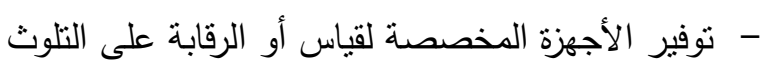

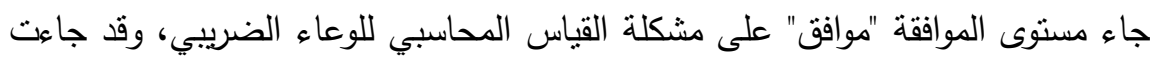

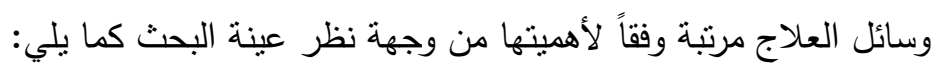
- فرض الضريبة على قيمة الأضرار الناتجة عن التلوث الناتج عن الاتبعاثات البيائية

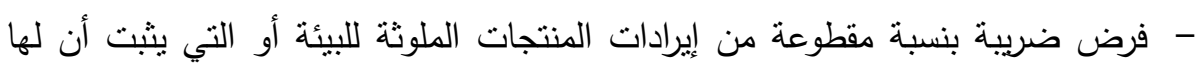
ضررا بالبيئة. - فرض ضريبة بمبلغ يزيد عن تكلفة إزالة الملوثات الناتجة عن الاتبعاثات البيئية للمنشأة. - فرض الضريبة على وزن المخالفات الملوثة التي تم صرفها وليس على أساس الحجم.

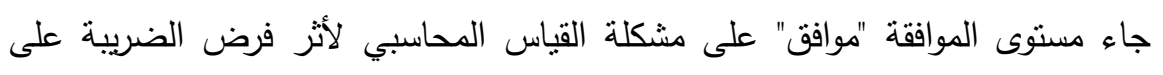

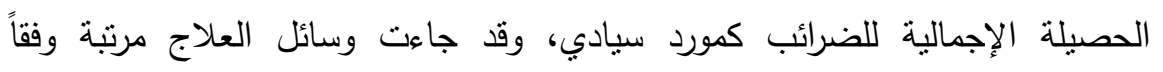

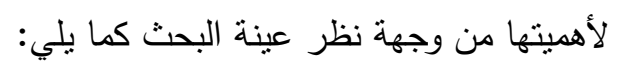

- يعتمد المستوى الأمتل لتقليل التلوث على مرونة الإيرادات الضريبية فيما يتعلق بالمعدل

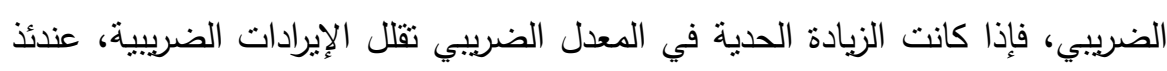
يصبح من الملائم تحديد معدل ضريبى منخفض، وخفض مسنوى النلوث بأداة لندبير الإيراد وليس بأداة لا تزيد الإيرادات.

- فرض ضريبة على الانبعاثات البيئية لن يؤثر بالسلب على حصيلة الضرائب الإجمالية.

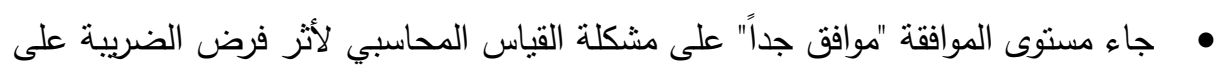

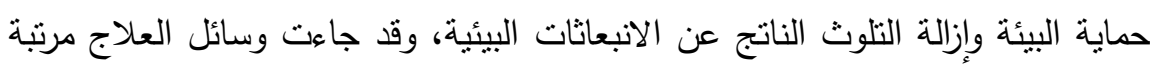
من وجهة نظر عينة البحث كما يلي: - تحديد نوع الضرر المنوقع من التلوث الناتج عن الانبعاثات البيئية. - - القياس النقدي لإزالة الضرر المتبقي. - تحديد حجم الضرر أو القياس الكمي للضرر الناتج عن الانبعانات البيئية.

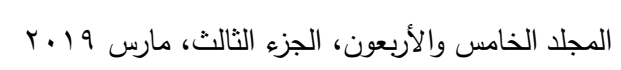




$$
\text { - تحديد القياس (الوزن) الفني لوحدة الضرر . }
$$

- تقييم جدوى وكفاءة فرض الضريبة لحماية البيئة ومكافحة التلوث الناتج عن الانبعاثات لفيدرة البيئية الناشئ من عمليات الإنتاج والتصنيع وهن - القياس النقدي لوحدة الضرر . جاءت مستوى الموافقة على الفجوة بين الربح المحاسبي والربح الضريبي، وقد جاءت لهات

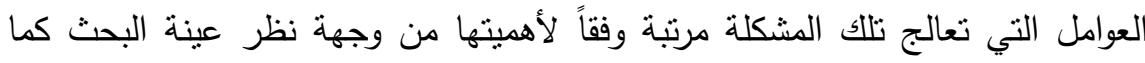

- المعالجة الضريبية الناتجة عن الانبعاثات البيئية واعتبارها من التكاليف واجبة الخصم يؤدي إلى خفض الفجوة بين الربح المحاسبي والربح الضريبي

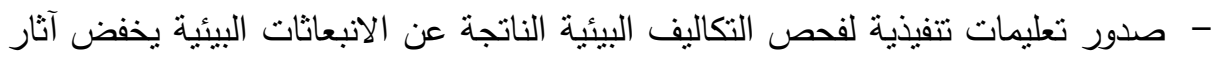
الحكم الثخصي للفاحص الضريبي - القصور في الاعتراف بالتكاليف الناتجة عن الانبعاثات يترتب عليه اتساع الفجوة بين الربح المحاسبي والربح الضريبي. - إدراج بند خاص للتكاليف البيئية الناتجة عن الانبعاثات البيئية في الإقرار الضريبي يخفض الفجوة بين الربح المحاسبي والربح الضريبي

ثالثا: نتائج خاصة بفروض الاراسة: قامت الدراسة على فرضين رئيسيين حيث أثنتت الدراسة الآتي: - تم رفض الفرض الأول للباحث: لا توجد علاقة ذات دلالة إحصائية بين معالجة

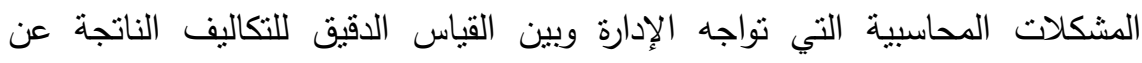
الانبعاثات البيئية. - تم رفض الفرض الثاني للباحث: لا توجد علاقة ذات دلالة إحصائية بين اختلاف

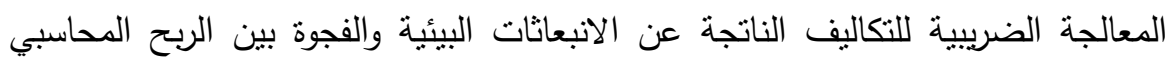

$$
\text { والربح الضريبي. }
$$




\section{اللموكياني}

في ضوء النتائج التي توصلت إليها الدراسة الميدانية يوصي الباحثون بما يلي:

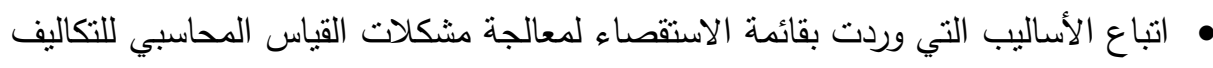
الناتجة عن الانبعانات البيئية، وكذلك المعالجة الضربيية والمحاسبية لتلك التكاليف، حيث التيث ثتتت فعاليتها وأهميتها من وجهة نظر عينة البحثن. • معالجة مشكلات القياس المحاسبي للتكاليف الناتجة عن الانبعاثات البيئية ويجب البهاء البهاء بالتحديد الدقيق لمعايير القياس المحاسبي البيئي، ثم معالجة صعوبات التكاليف الناتجة عن الانبعاثات البيئية، وعلاج المشكلات التي تواجه المجتمع في القياس البيئي، وعلاج مشكلة تحديد الإجراءات التي ستتبع في القياس المحاسبي البيئي، علاج مشكلة تحديد

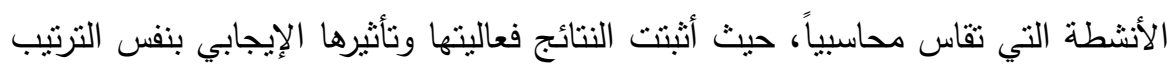
على القياس الدقيق للتكاليف الناتجة عن الانبعاثات البيئية.

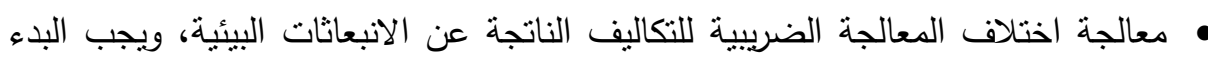
بعلاج مشكلة القياس المحاسبي لأثز فرض الضريبة على حماية البيئة وإزالة التلوث الناتج الناتئه

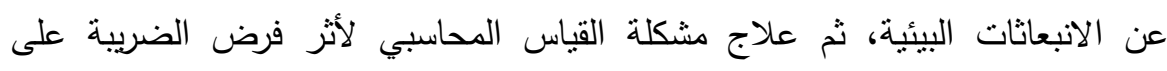

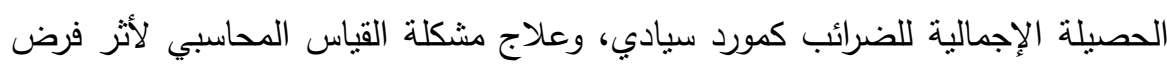

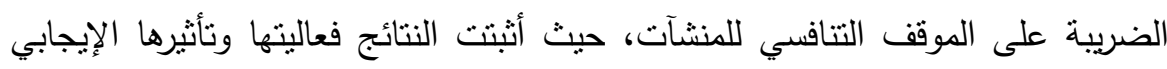
بنفس الترتيب على تضييق الفجوة بين الربح المحاسبي والربح الضريبي.

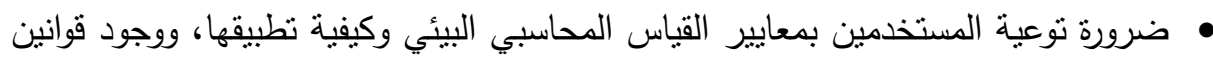

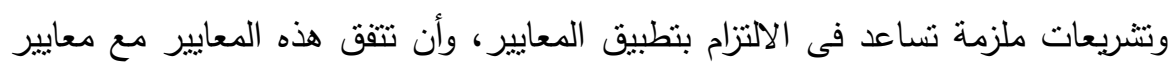
المحاسبة الدولية. إلزام الثركات بتحديد نسبة مساهمة تكاليف البيئة إلى إجمالي تكاليف المشروع، وقياس المنافع مثل المساعدات الحكومية والمنح والإعفاءات الضريبية وغيرها، ونسبنها إلى كل إنل من هذه التكاليف، وتحديد قدرة نظام التكاليف على تحليل التكاليف الناتجة عن الانبعاثات

$$
\text { البيئية إلى ثابتة ومتغيرة وتحليل الاتحرافات فيها. }
$$

• ضرورة حصر المنافع المتوقعة وقدرتها على خفض التلوث البيئي وتخفيض تكاليف تلوث

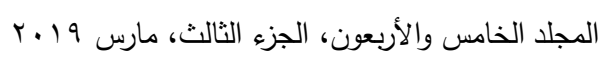


البيئة، وتحديد أثز الأنشطة البيئية على ارتفاع جودة المنتج أو الخدمة وما يترتب على ذلك من زيادة المنافع كزيادة الحصة السوقية أو رفع سعر بيع المنتج أو الخدمة.

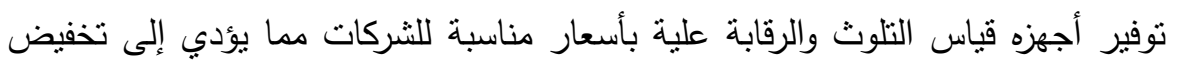
تكاليف قياس التلوث وخاصة في الصناعات ذات نسب التلوث البيئي المرتفعة، وضرورة عقد البرامج والدورات التدريبية لنوفير الكوادر الفنية المؤهلة للعمل في مجال البيئة. • إنشاء جهات رقابة أو مسئولة عن حصر وتجميع البيانات عن كافة المؤسسات لتحديد أنماط الإنتاج وأية أنشطة أخرى ذات علاقة بالانبعانات البيئية، وتحديد قيمة وحجم التكلفة الناتجة عن القياس البيئي مقارنه بالعوائد. ضرورة استحداث نشريع ضريبي يشجع على الالتزام بالحد من الآثار السلبية للتلوث

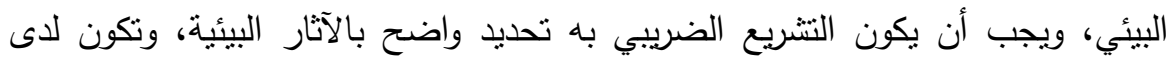

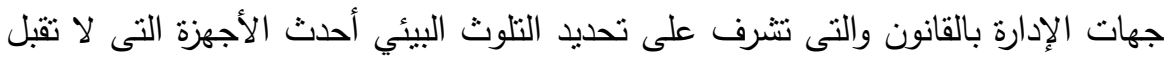
الثك لحصر التلوث وإثباته فى مكان عمل المنشآت. تحديد نوع الضرر المتوقع من التلوث الناتج عن الانبعاثات البيئية، وتحديد حجمهات، وتحديد

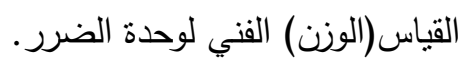

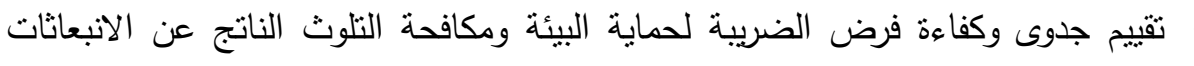

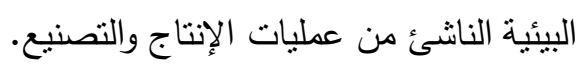
• ضرورة إقامة نظام معلومات بيئية بساعد على توفير المعلومات من أجل قياس تكاليف أضرار التلوث ومعالجته لتحسين إدارة البيئة.

\section{2all}

حجاج، أحمد حامد سعد وآخرون: "إطار محاسبي مقترح لقياس وتحليل التكاليف البيئية خلال

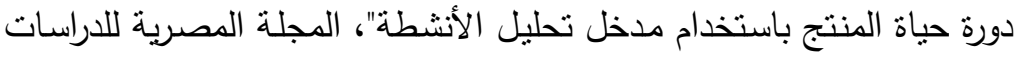

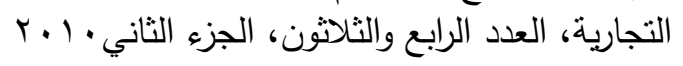




$$
\text { أبو الوفا أمين صادق أحمد وآخرون }
$$

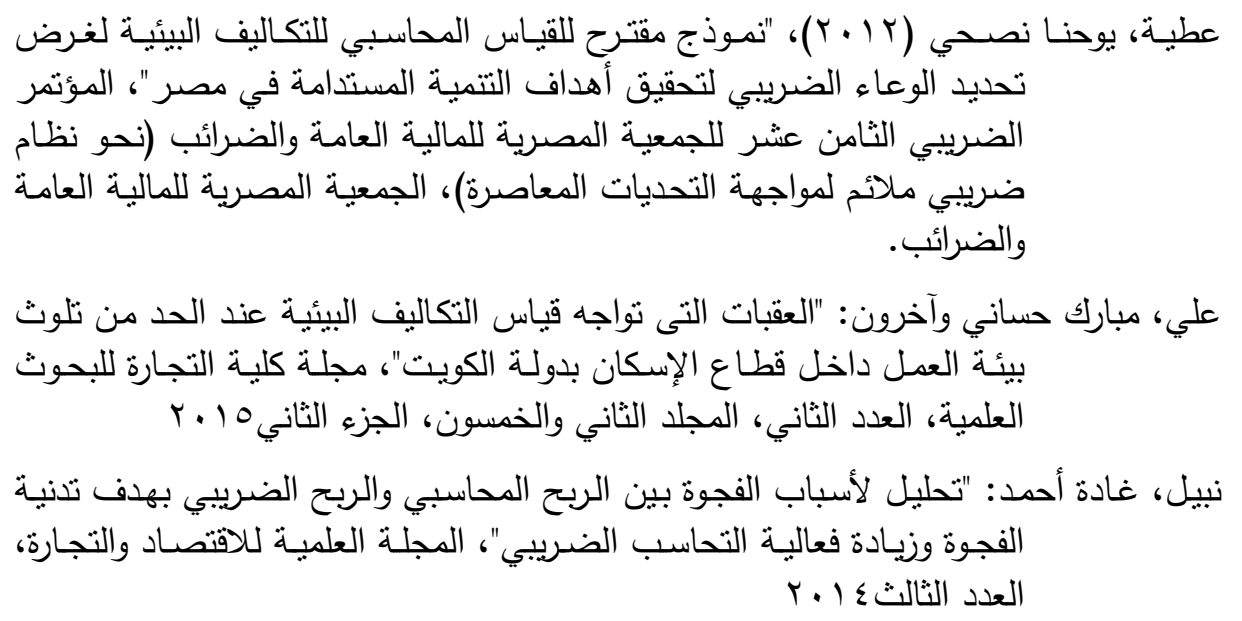

Jirásková, Simona \& Molín Jan, (2015), IFRS Adoption for Accounting and Tax Purposes: An Issue Based on the Czech Republic as Compared with Other European Countries, 16th Annual Conference on Finance and Accounting, ACFA Prague 2015, Economics and Finance, Vol. 25, May,

Ramirez, Constancio Zamora et al., (2014): Contabilidad del impuesto sobre beneficios y resultado global: relevancia valorativa en el mercado financiero espaňol, Revista de Contabilidad, Spanish Accounting Review, Vol. 17 (2).

Sief, Hanane Saidi, (2014) Accounting Framework to Measure the Environmental Costs and Disclosure in Industrials Companies-Case Study of Société Cement Hamma Bouziane (SCHB) in Constantine, Chinese Business Review, ISSN 1537-1506, Vol. 13, No. 6, June. 
مجلة العلوم البيئية

معهد الدراسات والبحوث البيئية - جامعة عين شمس لئس

\title{
A PROPOSED FRAMEWORK TO ADDRES ACCOUNTING AND TAX PROBLEMS OF COSTS RESULTING FROM ENVIRONMENTAL EMISSIONS
}

\author{
Abouelwafa A. S. Ahmed ${ }^{(1)}$;Samasm K. Moussa ${ }^{(2)}$ \\ and Shreen S. Maarouf ${ }^{(2)}$ \\ 1) Institute of environmental studies and Research, Ain Shams \\ University 2) Faculty of Commerce, Ain Shams University
}

\begin{abstract}
This study aimed to develop a proposed framework to treat accounting and tax problems of costs resulting from environmental emissions and to determine the difference between the accounting treatment of the tax treatment of costs resulting from environmental emissions and its impact on the gap between accounting profit and tax profit.

In order to achieve this goal, the researcher relied on theoretical rooting through the inductive method of books, references, and Arab and foreign studies, and then conducting a field study by designing a survey list of tax examiners in the tax authority, employees of financial departments and cost departments in Egyptian organizations and establishments, In the field of study to benefit from the academic and theoretical experience in the subject of the study. The sample included 92 members of the study community who showed a willingness to participate in answering the questionnaire.

The study concluded that there is a significant correlation between the accounting problems treatment faced by management and the accurate measurement of costs resulting from environmental emissions and there is a significant correlation between the difference in tax treatment of the costs resulting from environmental emissions and the gap between the accounting profit and the tax profit. The study recommended following the Techniques in the survey list to treat the
\end{abstract}

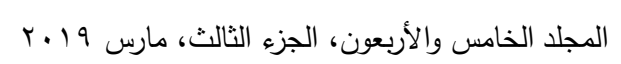


problems of accounting measurement for the costs resulting from environmental emissions, as well as the tax and accounting treatment of these costs, which proved to be effective and important from the point of view of the research sample. 